\title{
Control of $\mathrm{pH}$ of retained water in the coastal waste disposal site
}

\author{
Ramrav Hem ${ }^{1, *}$, Tomohiro Yamasaki ${ }^{1}$, and Hiroko Sumida ${ }^{1}$ \\ ${ }^{1}$ Geoenvironment Laboratory, Technical Research Institute, Toyo Construction Co., Ltd., \\ 1-25-1, Naruohama, Nishinomiya City, Hyogo Prefecture, 663-8142, Japan
}

\begin{abstract}
After landfilling of wastes is completed, the stabilization of landfilled ground requires much time and cost. Therefore, this study aimed to control the $\mathrm{pH}$ of retained water in the coastal waste disposal sites during landfilling process, by conducting field surveys and laboratory experiments. In field surveys, we investigated the changes of retained water quality such as $\mathrm{pH}$, salinity, and dissolved oxygen. The results show the $\mathrm{pH}$ of retained water has risen to about 10 when the volume of landfilled wastes reached about $25 \%$ of landfill capacity. In lowing the $\mathrm{pH}$, we considered a low-cost method by pumping seawater from the adjacent sea into the landfill. The mechanism in this method is that, $\mathrm{H}^{+}$dissociated from $\mathrm{HCO}_{3}^{-}$in the fresh seawater react with $\mathrm{OH}^{-}$eluted from wastes would result in $\mathrm{pH}$ decrease. The laboratory experiments were conducted to verify the effect on $\mathrm{pH}$ change by adding fresh seawater to alkalized seawater. As a result, the effect of injecting fresh seawater into alkalized seawater with $\mathrm{pH}$ higher than 9 was confirmed. Therefore, this treatment method is suggested to enable the disposal sites to be used promptly after landfilling is completed, by adding fresh seawater to purify the retained water and waste at low cost during landfilling process.
\end{abstract}

\section{Introduction}

In Japan, especially in the metropolitan areas with narrow in-land spaces, waste disposal facilities are built at the coastal and sea areas. It is known that seawater has $\mathrm{pH}$ buffering capacity [1]. However, at some disposal sites where the landfilling is almost completed, the retained water and pore water within landfill ground become high alkaline with $\mathrm{pH}$ of 11 or more. Therefore, the landfilling may be completed, while the $\mathrm{pH}$ is still high [2]. In order to use these sites, e.g., for factory or industrial land-use, after the landfilling is completed, the quality of the leachate generated during rainfall must satisfy the standard, e.g., $\mathrm{pH}$ of 9.0 or less. However, the $\mathrm{pH}$ of pore water in the landfilled ground remains high at most of the landfill sites, where the long-term treatments are required. This is because the alkaline components and organic components contained in the landfilled wastes become the pollution sources and those components will continue to release into the pore water in the landfill ground for a long time.

The countermeasures applied to purify the landfilled ground after the landfilling is complete such as "active washout using rainfall" and "forced drainage using a catchment underdrain" [3] were reported. Since the landfill sites were landfilled with various kind of wastes, the landfill ground may have different water permeability and air permeability. For that reason, although the purification can be promoted in the landfill ground with large grain size that makes it easy to flow through and ventilate, but it is not effective for the ground with small grain size due to its low permeability.

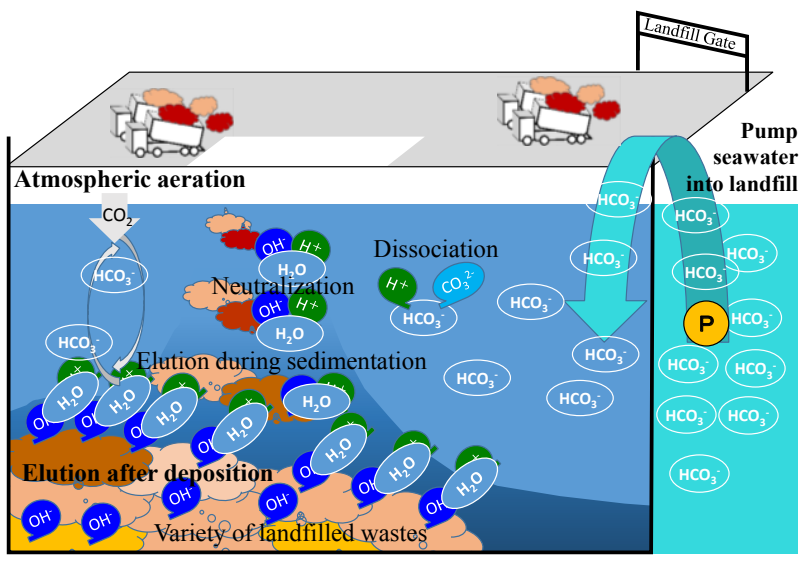

Fig. 1. Image of countermeasure and chemical reaction in retained water during landfill process

In such a case, in order to close the disposal sites, it is inevitable to choose uncertain or uneconomical countermeasures after the landfilling is completed.

As mentioned above, there is a need for a technology to quickly stabilize the leachate generated from the landfill ground, so that the disposal site can be closed early by implementing some countermeasures during the landfilling process, before the site is completed which makes it difficult to be purified. Therefore, in our research project, by focusing on the $\mathrm{pH}$ as the target of water quality, we assumed some prospective countermeasures that can be applied during the landfilling process. Those countermeasures are to maintain the buffering capacity of the retained water as much as possible before the

\footnotetext{
* Corresponding author: hem-ramrav@toyo-const.co.jp
} 
landfilling is completed.

Among those countermeasures, in this paper, we present only the countermeasure with the pumping up of the fresh seawater into the retained water in the landfill site to lower the $\mathrm{pH}$ and to enhance the buffering capacity of the retained water (See Figure 1).

In this paper, we attempted to control the $\mathrm{pH}$ of retained water in the coastal waste disposal site during the landfilling process, by conducting field surveys and two separated laboratory experiments.

\section{Field surveys}

\subsection{Method}

\subsubsection{Study site}

The study site, namely, Port of Kinuura No. 3 Coastal Waste Disposal Site, is located in Taketoyo-cho, Chitagun, Aichi prefecture, Japan (see Figure 2a). With the total capacity of $496 \mathrm{Mm}^{3}$, the site is divided into 2 compartments for stable waste (8.4 ha) and for controlledtype waste (34.4 ha) [4]. However, in this study, we focused on only the compartment for controlled-type waste which receive mainly fly ash. The landfill operation started to receive the waste in March 2011, and in March 2017 , the volume of the landfilled waste was estimated to be about $25 \%$ of its total capacity.

\subsubsection{Survey locations and dates}

In order to investigate the changes of water quality of the retained water in this landfill site, four times of surveys had been conducted in summer and winter seasons from 2015 [5] to 2017. Figure 2b shows the survey locations, one location (Point $\mathrm{C}$ ) is at the central part where water depth is relatively deep and the other four locations are at the East, West, South, and North parts of the site, where the water depths are relatively shallow.
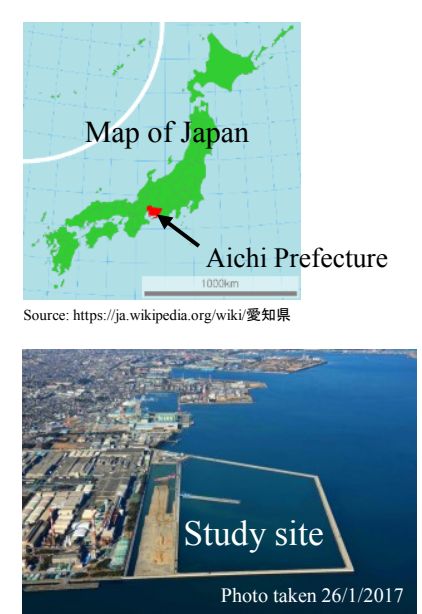

a)

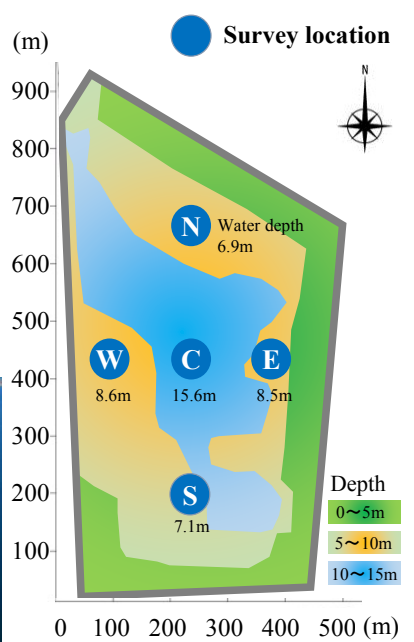

b)

Fig. 2. a) Study site location and aerial view and b) survey locations and water depth

\subsubsection{Survey equipment}

In the surveys, the vertical distribution of $\mathrm{pH}$, water temperature, DO, and salinity were observed by using a Multi-Parameter Water Quality Sonde (YSI 6600 V 2-4). In addition, we collected water samples basically at a $2 \mathrm{~m}$ interval from the water surface to conduct the laboratory analysis for $\mathrm{pH}$, bicarbonate ion $\left(\mathrm{HCO}_{3}{ }^{-}\right)$, dissolved metals (e.g., calcium, magnesium, iron, and aluminium), salinity, and chloride ion concentration.

\subsection{Results and discussion}

There was no difference between the observation values and the analysis values of the same depth in all the survey locations for all investigation days. From these results, in all the survey locations are assumed to be uniform in horizontal plan of the whole landfill site. Therefore, in this paper, only the data at point $\mathrm{C}$ is presented. Figure 3 shows the observation results at point $\mathrm{C}$. From the survey results of 2017/1/31, the graphs show the $\mathrm{pH}$ increased with progress of landfilling, which were almost 10 from the top surface to middle layers and over 10 in the bottom layer. As for water temperature, the thermocline (steep vertical temperature gradient) occurred at the depth of 5 6 $\mathrm{m}$ in summer, but due to mixing due to high temperature in winter, it was uniform except the bottom layer. Salinity increased with the progress of landfill, and in the bottom layer it exceeded $40 \%$, and salinity halocline (steep vertical salinity gradient) developed at about $12 \mathrm{~m}$ in depth. Due to the influence of this halocline, water temperature, DO of water mass of 2017/1/31 was formed in the state that is not vertically mixed.

Figure 4 shows the results of samples analysis of point C. $\mathrm{HCO}_{3}{ }^{-}$decreased with the landfill progress, which was equivalent to less than a half of the value of general sea area (about 100 to $120 \mathrm{mg} / \mathrm{L}$ ). Calcium as a whole was higher than general sea area (about 300 to $400 \mathrm{mg} / \mathrm{L}$ ), and it was higher at the bottom layer. Magnesium was lower than the value of the general sea area (about 1000 to 1300 $\mathrm{mg} / \mathrm{L}$ ), and it was lower and lower at the bottom layer. The value also has decreased with the progress of landfill. According to the above results, it is considered that the chemical reactions as shown in the below chemical equations, modified from [1], occurred particularly in the vicinity of the bottom layer.

$$
\begin{aligned}
& \mathrm{Ca}(\mathrm{OH})_{2} \Leftrightarrow \mathrm{Ca}_{2}^{+}+2 \mathrm{OH}^{-} \\
& \uparrow \text { Supplied from ash } \quad \uparrow \text { Increase in seawater }
\end{aligned}
$$

$\mathrm{HCO}_{3}{ }^{-} \Leftrightarrow \mathrm{H}^{+}+\mathrm{CO}_{3}{ }^{2-}$

$\uparrow$ Decrease in seawater

$\mathrm{OH}^{-}+\mathrm{H}^{+} \Leftrightarrow \mathrm{H}_{2} \mathrm{O}$

$\mathrm{Mg}^{2+}+\mathrm{CO}_{3}{ }^{2-} \Leftrightarrow \mathrm{MgCO}_{3} \downarrow$ 


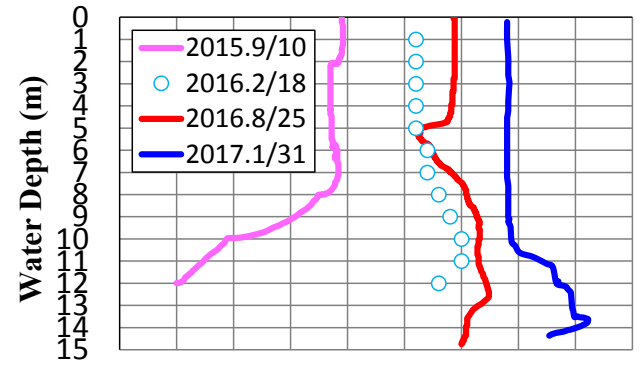

$6.5 \quad 7.07 .5 \quad 8.0 \quad 8.5 \quad 9.0 \quad 9.510 .010 .511 .0$ pH

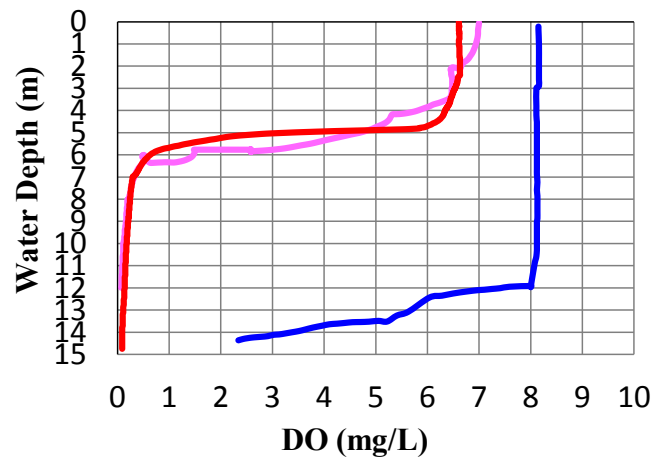

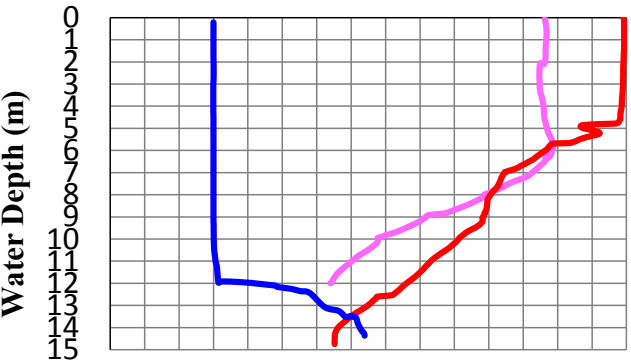

024681012141618202224262830 Water temperature $\left({ }^{\circ} \mathrm{C}\right)$

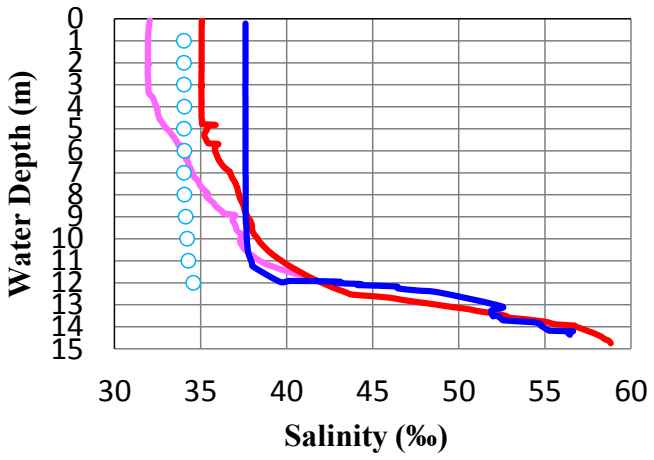

: Analytical value

Fig. 3. Survey and analytical results of retained water quality (Point C)
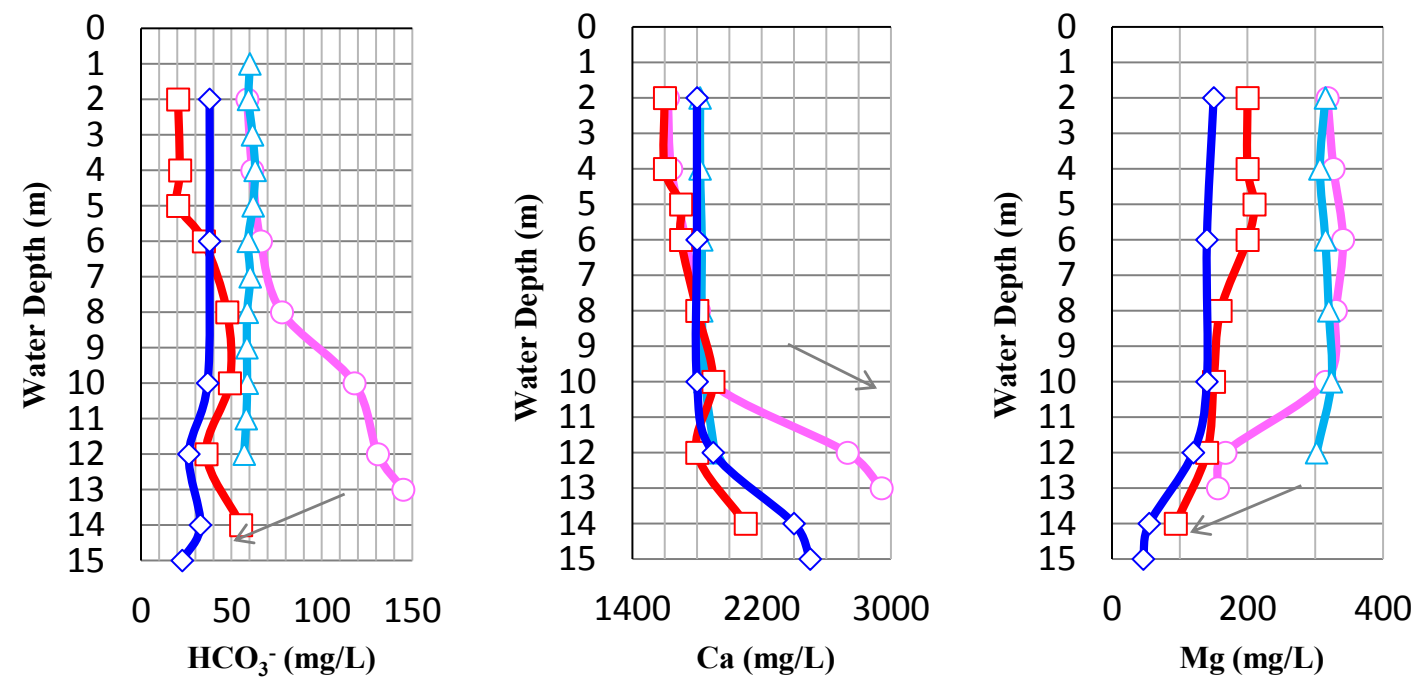

Fig. 4. Analytical results of retained water quality (Point C)

\section{Laboratory experiments}

\subsection{Background}

Two different laboratory experiments were carried out, separately. In both experiments, we used exactly the same fly ash taken from the site and artificial seawater made with same initial $\mathrm{pH}$ of about 8.2. Immediately after receiving the sample, we carried the sieve analysis for particle size distribution of fly ash. However, as show in Figure 5, the particle size of fly ash used in in the first experiment ranged from 0.85 to $2 \mathrm{~mm}$, while particle size of less than $0.25 \mathrm{~mm}$ in the second experiment. With the smaller particle size of fly ash, we expected to have higher $\mathrm{pH}$ in the second experiment. Vertical pipes which assumed to be representative of the real landfill site in 1 dimensional vertically. However, the pipe length used in the first experiment is shorter than that of the second experiment.

By using short pipes, the experiment could be easily carried out to investigate the $\mathrm{pH}$ changes corresponding to different cases of water injection. However, with short pipes, the $\mathrm{pH}$ decrease due to not only from the effect of 


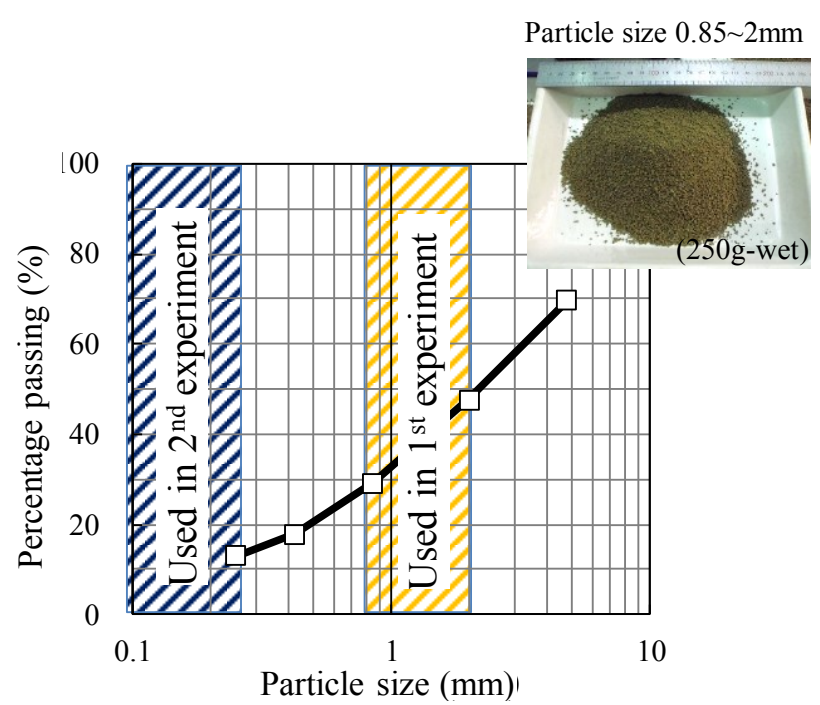

Fig. 5. Particle size of fly ash used in the experiments

the fresh seawater injected, but also from of $\mathrm{CO}_{2}$ in atmosphere dissolved into alkaline seawater during experiment. Therefore, the second experiment was carried out with a longer pipe to investigate the depth of $\mathrm{CO}_{2}$ influence and to clearly confirm the effect of fresh seawater injection.

The same $\mathrm{pH}$ meter (PH-230SDJ PE-21, Sato Corporation) has been used in both experiments. The $\mathrm{pH}$ meter can be used to continuously measure the $\mathrm{pH}$ at any depth by directly plunging into the seawater in the pipes.

\subsection{Seawater injection experiment}

\subsubsection{Method}

As shown in Figure 6, we used three acrylic pipes with an internal diameter of $10 \mathrm{~cm}$ and height of $1 \mathrm{~m}$. At first, 5.0 L (height $63.7 \mathrm{~cm}$ ) of artificial sea water with the initial $\mathrm{pH}$ of about 8.2 was input into the acrylic pipes, and the vertical $\mathrm{pH}$ was measured at an interval of $5 \mathrm{~cm}$ from the overlying water surface. Next, fly ash of $2.0 \mathrm{~kg}$-wet was added little by little for 16 minutes. After that, it was left to stand for 24 hours, next, the vertical distribution of $\mathrm{pH}$ of overlying water was measured. And then, we started the injection of new artificial seawater using a small vertical pipe attached into the inside of each acrylic pipe. As shown in Table 1, the addition of new seawater, equivalent to $1 \%(50 \mathrm{~mL})$ and $4 \%(200 \mathrm{~mL})$ of the used seawater quantity, was carried out continuously every 24 hours for 6 days. The injection height of each case was set as shown in Table 1.

Table 1. Experimental cases for seawater injection

\begin{tabular}{|c|c|c|c|}
\hline Seawater injection & Case 1 & Case 2 & Case 3 \\
\hline Ratio (\%/day) & 1 & 1 & 4 \\
\hline Volume (mL/day) & 50 & 50 & 200 \\
\hline Injection height (cm) & 70 & 40 & 40 \\
\hline
\end{tabular}

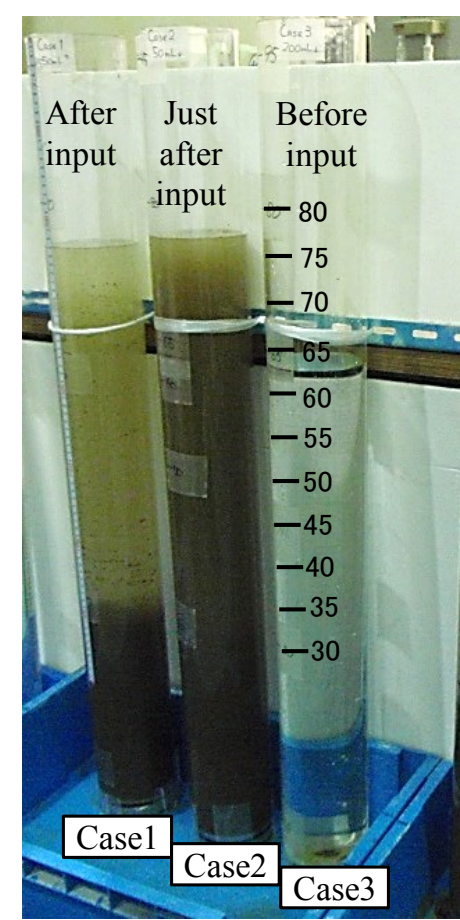

Fig. 6. Experiment conditions

\subsubsection{Results and discussion}

The changes of vertical distribution of $\mathrm{pH}$ before and after injection of new artificial seawater as a measure to lower the $\mathrm{pH}$ of alkaline seawater are shown in Figure 7. From the results, in Case 1, where the water injection height was $70 \mathrm{~cm}$ from the bottom surface of the acrylic pipe (about $5 \mathrm{~cm}$ below the overlying water surface), the $\mathrm{pH}$ from the injection position to the water surface greatly decreased. Similarly, in Case 2 and Case 3 with injection height of $40 \mathrm{~cm}$ from the bottom surface of the acrylic pipe $(10 \mathrm{~cm}$ on the deposit surface), the $\mathrm{pH}$ below the injection height tended to decrease. The tendency was more remarkable in Case 3 with greater water injection volume. The $\mathrm{pH}$ of overlying water just above the sediment surface was suppressed small in Case 3, where much water injection volume and low water inject height compared to Case 2 and Case1.

The surface of the ash deposit, after 24 hours of injection, was covered with white precipitate and increased with increasing seawater injection in all cases. From the above results, it is considered that, the nearer to he deposited ash layer, the higher density of overlying water. Accordingly, when the water with a relatively low density injected, it diffuses towards the water surface, while neutralized with only the shallow part of overlying water. Therefore, this result suggests that a deep injection of new seawater is effective to neutralize the retained water as a whole.

After the injection was completed, it was left to stand. On the $49^{\text {th }}$ day after injection, the overlying water and the deposited ash pore water of Case 3 were sampled and analyzed. Pore water was obtained by using a solid-liquid centrifuge separator. The analytical results of artificial sea 


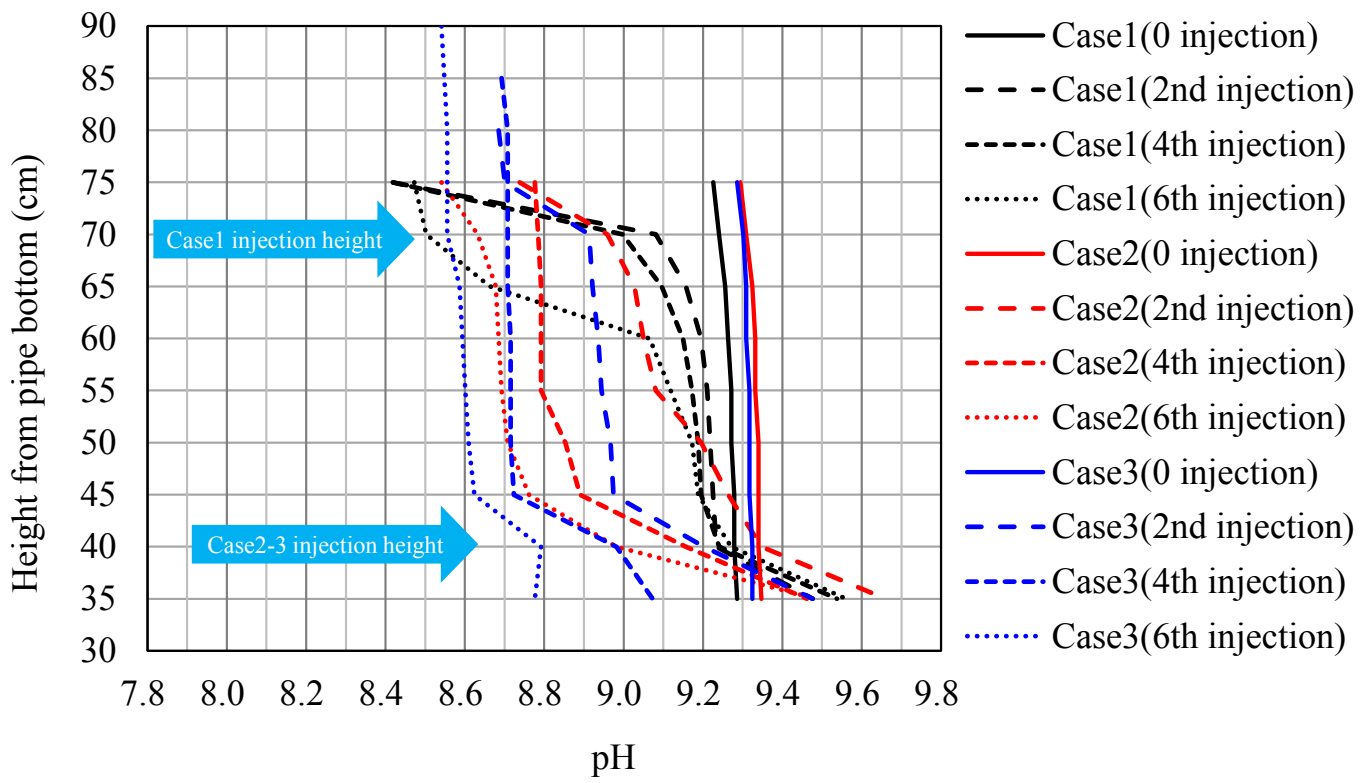

water before injection, overlying water, and pore water of Case 3 are shown in Table 2. Compared to the $\mathrm{pH}$ before being left to stand, the $\mathrm{pH}$ decreased as a result of atmospheric $\mathrm{CO}_{2}$ dissolution from the overlying water surface, and the bottom layer was rising due to the influence of high alkaline pore water released from the ash deposit. The amount of $\mathrm{HCO}_{3}{ }^{-}$was decreased from the surface of overlying water to just above and within the ash deposit. Concentration of $\mathrm{HCO}_{3}{ }^{-}$, in general sea water with the maximum $\mathrm{pH}$ of 8.25 , is about $90 \%$ at $\mathrm{pH} 9$ and about $50 \%$ at pH 10 (see Figure 8). From a certain proportion of the dissolved $\mathrm{HCO}_{3}^{-}$, the dissociated hydrogen ion $\mathrm{H}^{+}$(and carbonate ion $\mathrm{CO}_{3}{ }^{2-}$ ) is neutralized with $\mathrm{OH}^{-}$derived from waste which can be considered to suppress the rising $\mathrm{pH}$ of seawater [1]. Compared to general sea water, the experimental value of $\mathrm{HCO}_{3}{ }^{-}$is small in the range of $\mathrm{pH} 8.2$ to 9.5 , which indicates that it was consumed by the neutralization reaction. At $\mathrm{pH} 10.5$ it is considered that neutralization reaction does not occur because it is the same rate as general seawater. Therefore, the effect of injecting new seawater remarkably when the initial $\mathrm{pH}$ was 9.0 or more.

From the analytical results, the concentration of magnesium decreased downwards, and especially in the pore water. This is probably because the magnesium ion $\left(\mathrm{Mg}^{2+}\right)$ in the overlying water or pore water react with $\mathrm{CO}_{3}{ }^{2-}$ dissociated from $\mathrm{HCO}_{3}{ }^{-}$and form as precipitate of magnesium carbonate $\mathrm{MgCO}_{3}$, resulting in a decrease in dissolved concentration [1]. It is thought that the increased in the sediment at the surface layer of the sediment is caused by further neutralization and bonding reactions as the $\mathrm{pH}$ had increased.

\subsection{Effect of atmospheric $\mathrm{CO}_{2}$ and seawater injection experiment}

\subsubsection{Method}

In order to make $\mathrm{pH}$ of the overlying water higher than the above experiment, smaller particle size of fly ash (under

Table 2. Analytical results of artificial seawater, retained water, and pore water (Case 3)

\begin{tabular}{|c|c|c|c|c|c|c|}
\hline \multicolumn{3}{|c|}{ Items } & $\mathrm{pH}$ & $\mathrm{HCO}_{3}^{-}(\mathrm{mg} / \mathrm{L})$ & $\mathrm{Mg}(\mathrm{mg} / \mathrm{L})$ & $\mathrm{Ca}(\mathrm{mg} / \mathrm{L})$ \\
\hline \multicolumn{3}{|c|}{ Artificial seawater (before input) } & 8.16 & 207.4 & 1300 & 640 \\
\hline \multirow{9}{*}{ Case 3} & \multirow{8}{*}{$\begin{array}{l}\text { Height of the } \\
\text { overlying water } \\
\text { from the pipe } \\
\text { bottom }(\mathrm{cm})\end{array}$} & 85 & 8.29 & 116.1 & 1200 & 930 \\
\hline & & 80 & \multirow{3}{*}{ N.D. } & \multirow{3}{*}{ N.D. } & \multirow{3}{*}{ N.D. } & \multirow{3}{*}{ N.D. } \\
\hline & & s & & & & \\
\hline & & 55 & & & & \\
\hline & & 50 & 8.72 & 123.0 & 1100 & 1000 \\
\hline & & 45 & \multirow[b]{2}{*}{ N.D. } & \multirow{2}{*}{ N.D. } & \multirow{2}{*}{ N.D. } & \multirow{2}{*}{ N.D. } \\
\hline & & 40 & & & & \\
\hline & & 35 & 9.31 & 100.0 & N.D. & N.D. \\
\hline & \multicolumn{2}{|c|}{ Pore water in deposited ash } & 10.53 & 54.6 & 110 & 2600 \\
\hline
\end{tabular}




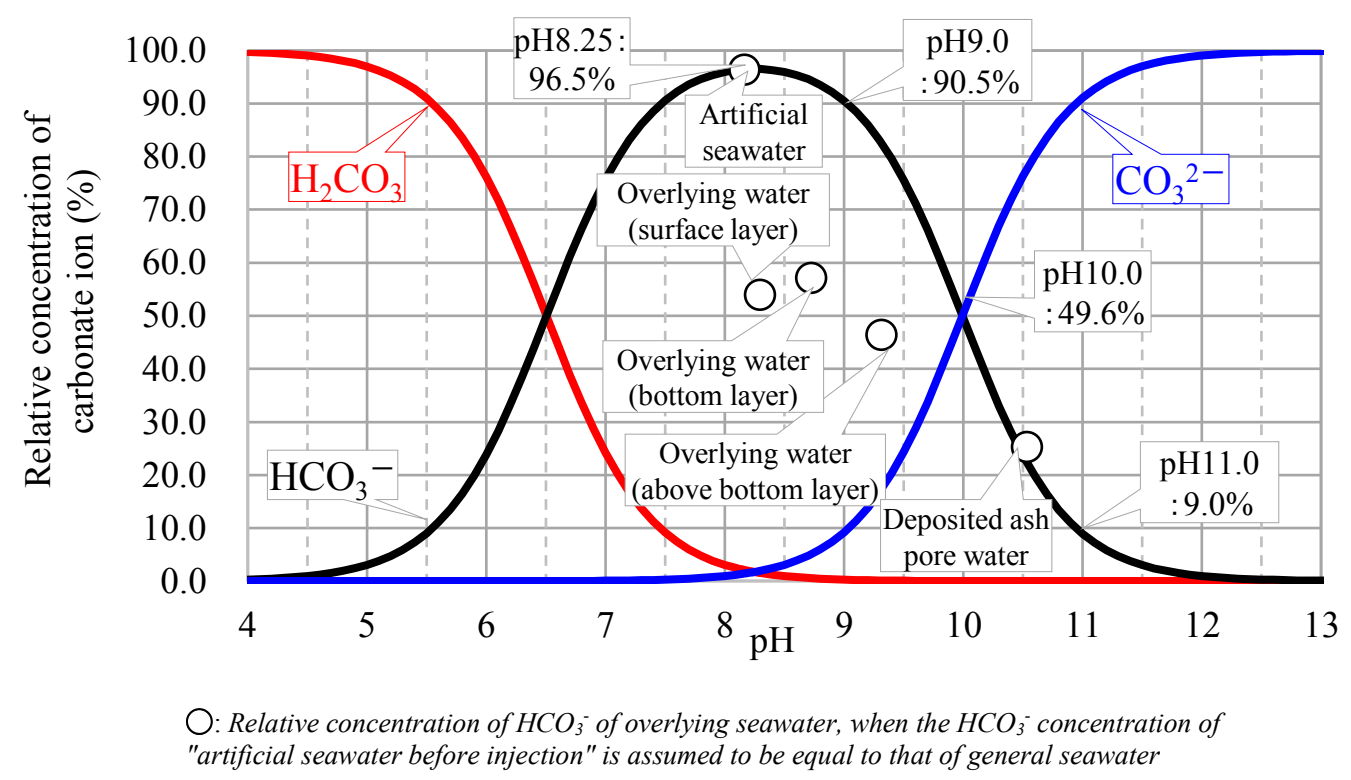

Fig. 8. Carbonate ion concentration of the general seawater and the experimental value

$0.25 \mathrm{~mm}$ ) was used. To clearly investigate the depth of influence of $\mathrm{CO}_{2}$ dissolved into the overlying water and effect of the seawater addition, the use of a longer PVC pipe of $6 \mathrm{~m}$ in length and $75 \mathrm{~mm}$ in inner diameter was considered.

At first, as shown in Figure 9 the PVC pipe was firmly affixed to the wall of the experiment pit inside our research facility, where the environment is calm without strong wind. Then, about $24 \mathrm{~L}$ of artificial seawater with $\mathrm{pH}$ of 8.2 was injected into the PVC pipe. After that, $5 \mathrm{~kg}$ of fly ash with water content $12.36 \%$ was input little by little. After 24, with an interval of $20 \mathrm{~cm}$ from the water surface, vertical distribution of $\mathrm{pH}$ of overlying water was measured.

As the injection method, a small PVC pipe was bended with 90 degree angle at the end so as not to allow the injected water drop below the exact depth, which was set to be about $2 \mathrm{~m}$ from the overlying water surface.

\subsubsection{Results and Discussion}

As a result, the average vertical distribution of $\mathrm{pH}$ of overlying water had been measured to be ranged from 11.0 to 11.5 for the first two months and a half, from the
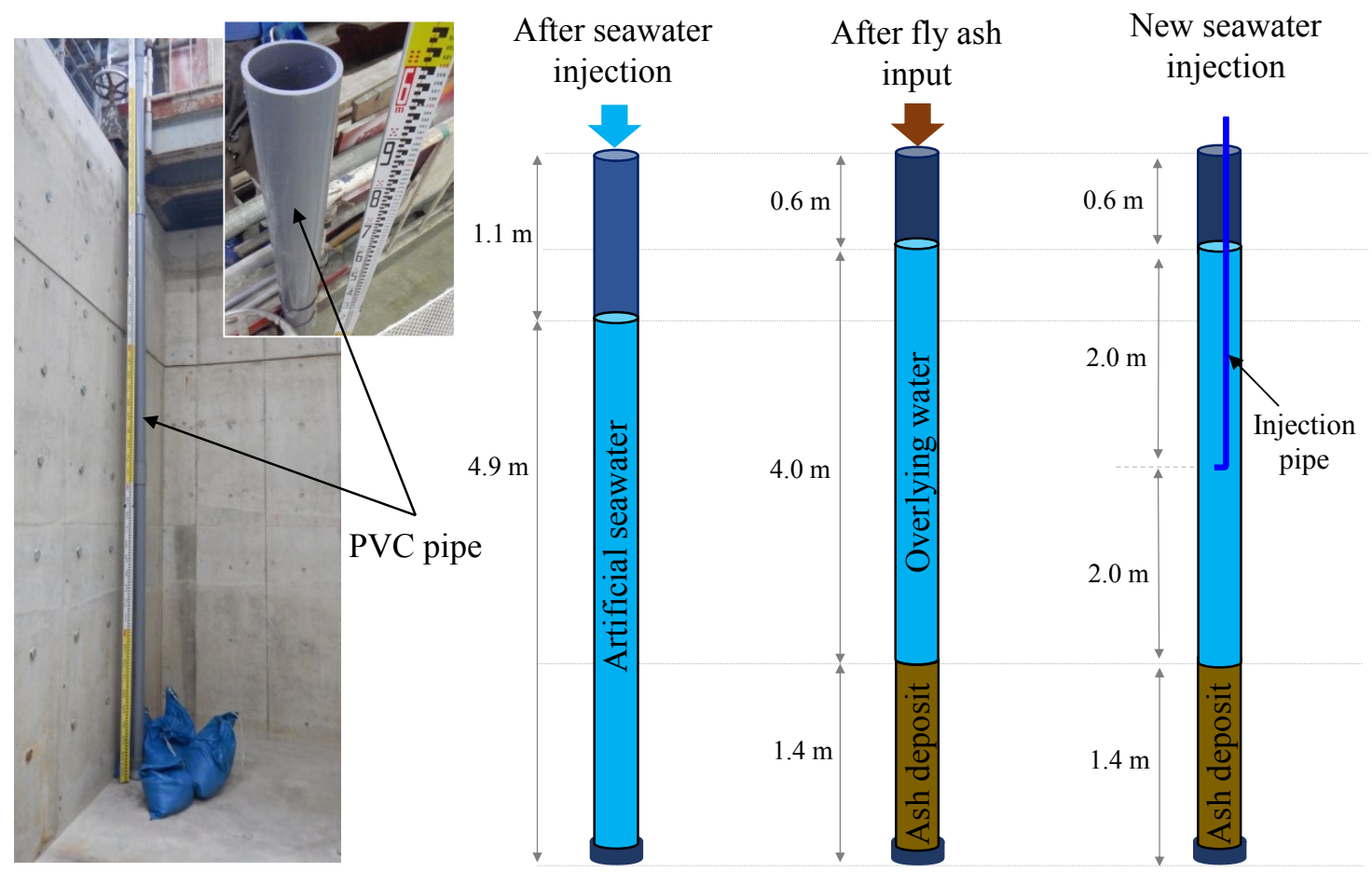

Fig. 9. Illustration of the second experimental condition 
beginning of the experiment. Based on the results during these period, the trend of vertical distribution of $\mathrm{pH}$ slightly decreased from the depth of $1 \mathrm{~m}$ downwards to the surface of overlying water. From this results, we could assumed that, under the effect of atmospheric aeration, $\mathrm{CO}_{2}$ may dissolve into the overlying water during experiment until the depth of about $1 \mathrm{~m}$ from the overlying water surface.

After 3 months from the beginning of the experiment, the average $\mathrm{pH}$ of overlying water, measured from the surface to the injection depth of $2 \mathrm{~m}$, was about 10.28. From then, we started to carry out the new artificial seawater injection. The first injection of about $220 \mathrm{~mL}$ of artificial seawater which was equivalent to about $1 \%$ of the total volume of the seawater initially used. After 24 hours, vertical distribution of $\mathrm{pH}$ was measured, and after that, immediately we carried out the second injection in the same way and the same amount of artificial seawater as the first injection. After 24 hours, the vertical distribution of $\mathrm{pH}$ was measured again. The results of vertical distribution of $\mathrm{pH}$ measured just before and after injection are shown in Figure 10.

We considered the average value of $\mathrm{pH}$ measured from the water surface to the injection depth of 2 with an interval of $20 \mathrm{~cm}$. The average $\mathrm{pH}$ was about 10.28 just before the injection, had dropped to about 10.14 at 24 hours after the first injection, and then, dropped to 10.07 at 24 hours after the second injection. And, at 48 hours after the second injection the average $\mathrm{pH}$ very slightly decreased to just little below 10.07. Although the injection depth was at $2 \mathrm{~m}$, however, the small effect of the seawater injection can be observed until the depth of 2.4 $\mathrm{m}$. On the other hand, the $\mathrm{pH}$ distribution below the depth of $2.4 \mathrm{~m}$ was slightly increase. This may be due to the pore water with high alkalinity continued to release from the deposited ash layer as time pasted.

From these experimental results, especially, $\mathrm{pH}$ at 24 hours after the first injection, the effect of adding new artificial seawater in lowering $\mathrm{pH}$ of alkaline seawater was clearly confirmed.

\section{Summary and concluding remarks}

In Japan, coastal waste disposal sites are generally built with large scale and high construction cost. To use the sites after landfilling is completed for, e.g., industrial land-use, it requires much time and cost for stabilization of landfill ground (leachate treatment) to meet the standards. Therefore, our study aimed to control the $\mathrm{pH}$ of retained water in the coastal waste disposal sites during the landfilling process, by conducting field surveys and laboratory experiments.

Water quality surveys of the retained water were conducted for two consecutive years (in summer and winter) at the study coastal waste disposal site. In summer, a thermochemical layer and a halocline layer were confirmed, and in winter, the halocline of the bottom layer was confirmed. In such an environment that the halocline derived from the landfill waste is not eliminated throughout the full term, even if, for example, some of purification measures applied from the surface layer to the middle layer, because the purification effect may not reach the deep seawater layer with high density.

As the landfill progresses, the $\mathrm{pH}$ has risen to nearly 10 , it is considered that the retained water in this study site reaches its buffering capacity limit [6] due to the decrease in $\mathrm{HCO}_{3}{ }^{-}$in the retained water, the increase in dissolved calcium concentration in the bottom layer, etc.

In order to control of $\mathrm{pH}$ of retained water of the study site, we consider a low-cost method by simply pumping seawater from the adjacent sea into the site. The added fresh seawater is rich in $\mathrm{HCO}_{3}{ }^{-}$. Therefore, the $\mathrm{H}^{+}$, dissociated from $\mathrm{HCO}_{3}^{-}$, react with $\mathrm{OH}^{-}$eluted from landfilled waste to result in lowering the $\mathrm{pH}$. With this mechanism the buffering capacity of the retained water can be maintained. From the results of the laboratory experiments, this measure was confirmed effective for the alkaline seawater with $\mathrm{pH}$ of 9 or over. Therefore, the study suggests this method as one of the effective and low-cost methods applied during landfill process, so the disposal site can used promptly after the landfilling is completed.

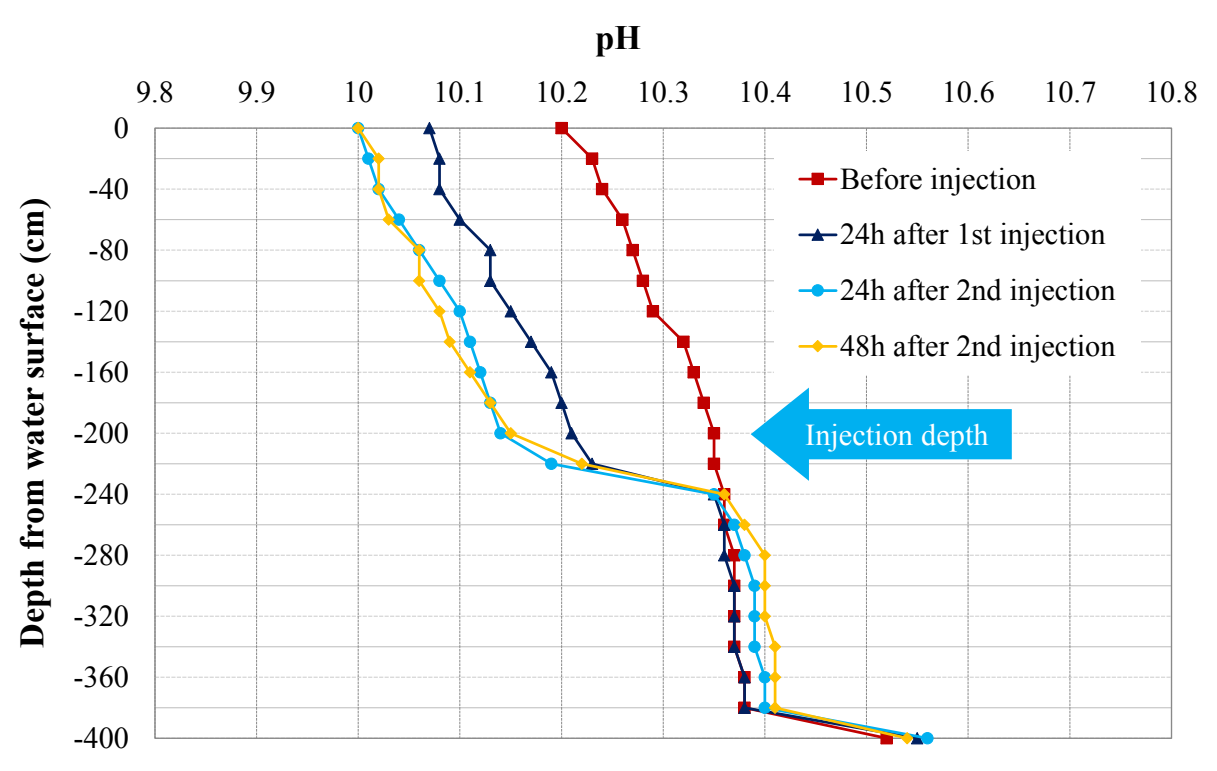

Fig. 10. Results of vertical distribution of $\mathrm{pH}$ before and after seawater injection 
The authors would like to thank ASEC (Aichi Seaside Environment Center) for allowing us to carry out research on this coastal waste disposal site. We are also grateful for its partial data provision for this paper.

\section{References}

[1] H. Sakanakura, N. Nakagawa, N. Maeda, Y. Kadota, S. Mizutani, K. Endo, K. Miyawaki, The 25rd Annual Conference of Japan Society of Material Cycles and Waste Management, No. 25, pp. 399-400 (2014). (In Japanese)

[2] JESC (Japan Environment Sanitation Center), Examination survey toward the technical standard of the sea area final disposal sites for closure or abolished, pp. 18 (2005). (In Japanese, title is unofficially translated by authors)

[3] J. Tsukahara, T. Oshima, T. Sakaki, N. Maeda, The Thirty-seventh Japan National Conference on Geotechnical Engineering, JGS37, pp. 2437-2438 (2002A). (In Japanese)

[4] ASEC (Aichi Seaside Environment Center), Environmental Activities Report (Activity period: April 2016 March 2017), Issued 1 April 2017 (in Japanese). Link: http://www.asec.or.jp/images/profile/p_report.pdf

[5] T. Yamasaki and H. Sumida, Proceedings of the 27th Annual Conference of Japanese Society of Material Cycles and Waste Management, pp. 421422 (2016). (In Japanese)

[6] T. Yamasaki, R. Hem, and H. Sumida, Journal of Japanese Association for Coastal Zone Studies, $\mathbf{2 8}$, No. 3, pp. 41-49 (2015). (In Japanese) 